\title{
Industrial wastewater treatment wastes used as oxygen carriers in energy generation processes
}

\section{A green chemistry approach}

\author{
Ewelina Ksepko $^{1}$ Joanna Klimontko ${ }^{2,3} \cdot$ Anna Kwiecinska $^{4}$
}

Received: 14 October 2018/Accepted: 22 March 2019/Published online: 5 April 2019

(c) The Author(s) 2019

\begin{abstract}
The paper contains the results of a study on a promising combustion technology known as chemical looping combustion (CLC). The main advantage of CLC is the production of a highly concentrated $\mathrm{CO}_{2}$ stream without any energy penalty for its separation, together with $\mathrm{NO}_{x}$ emissions reduction. The objective of this work was to examine novel oxygen carrier (OC) materials for their practical applications with gaseous fuel/air. We report a simple, economical and environmentally friendly method for the large-scale synthesis of OCs from wastes. The reactivity tests for OCs made from wastewater from a coking plant were performed in a thermogravimetric analyser. For selected temperatures, reduction-oxidation cycles were performed. The effect of temperature on the reaction rates, the effect of waste treatment and the oxygen transport capacity were determined. The waste material demonstrated good thermal stability and maintained its redox behaviour over cycling. ICP-OES and XRD data revealed these materials that contained beneficial amounts of Fe species and silicon oxide, which improved stability. The study showed that these waste materials are excellent examples of raw materials that can enable a decrease in OC production costs with the additional benefit of the practical management of post-wastewater sediments from coke oven wastewater plants.
\end{abstract}

Keywords Coking wastewater - Electrocoagulation - Chemical looping combustion - Natural oxygen carrier .

$\mathrm{TG} \cdot \mathrm{XRD} \cdot \mathrm{SEM}$

In this paper, chemical looping combustion (CLC) study results are presented. CLC has an advantage over other known fuel combustion technologies in that it enables the production of a concentrated $\mathrm{CO}_{2}$ stream without any energy penalty for its separation or purification [1]. Therefore, in contrast to conventional combustion methods

Ewelina Ksepko

ewelina.ksepko@pwr.edu.pl

1 Department of Chemistry and Technology of Fuels, Wroclaw University of Science and Technology, 7/9 Gdanska, 50-373 Wroclaw, Poland

2 A. Chelkowski Institute of Physics, University of Silesia, 75 Pulk Piechoty 1A, Chorzow, Poland

3 Silesian Centre for Education and Interdisciplinary Research, University of Silesia, 75 Pulk Piechoty 1A, Chorzow, Poland

4 Institute for Chemical Processing of Coal, 1 Zamkowa, 41-803 Zabrze, Poland where carbon capture is applied, it prevents a substantial efficiency decrease. In addition, other greenhouse gas components such as $\mathrm{NO}_{\mathrm{x}}$ are reduced in this technology $[2,3]$. The basic idea is to avoid direct contact between the fuel and the combustion air. This can be realized by using an oxygen carrier (OC), which is usually made from d-block metal oxides. These metal oxides are called oxygen carriers, and they are used to transport oxygen to the fuel instead of using direct mixing of fuel and air. To date, various potential oxygen carriers have been recognized. Usually, OCs are composed of oxides or mixtures of various metal oxides. They contain, for example, various compositions of iron, copper, manganese and cobalt oxides, which are used as active materials. They may also include aluminium, silica, titanium and zirconium oxides, which are known as inert materials [4]. The inert materials are added to the active metal oxides to improve the overall OC lifetime, by leading to sufficient attrition and/or by improving their thermal resistivity. There are many 
challenges associated with a proper OC material design for the CLC process. Among other characteristics, researchers are looking for OCs with high reactivity, satisfactory oxygen transport capacity, satisfactory mechanical strength and a low agglomeration tendency [5]. Furthermore, to successfully implement CLC technology, huge amounts of cheap carriers are required. CLC literature data show that in the past the development of suitable synthetic oxygen carrier materials [6-8] was intensive, with special attention paid to diverse preparation methods and different chemical compositions. On the other hand, nowadays increasing research interest can be observed in naturally occurring materials f or CLC purposes. Successful examples include testing of minerals $[9,10]$, natural ores such as iron or iron-manganese ores [9] or industrial wastes [11, 12] which have all been considered as low-cost oxygen carriers. In addition, a few other options for using economically feasible materials have been investigated, such as sewage sludge ash [13], which showed potential for use in the direct coal combustion process in a loop. The successful results were proved by TG-MS examination. Crucially, these results were verified by XRD and SEM and it was demonstrated that the Fe-based carrier was clearly coal ash resistant. Zhang et al. [12] investigated $\mathrm{Fe}_{2} \mathrm{O}_{3}$-containing wastes from the steel industry for Chinese bituminous coal chemical looping combustion. The authors observed an increased reactivity and porosity with an increasing number of reduction cycles and increased carbon conversion.

The technology of the wastewater treatment process and the selection of the most economically and technologically advantageous solutions depend on the nature of the pollutants in the wastewater and on the degree of purification necessary [14]. Coagulation is a process commonly used in wastewater treatment. An important part of this process is the reduction in the degree of dispersion of the system due to agglomeration of particles, which can then be easily removed in the sedimentation/flotation process. As a result of coagulation, particles which are difficult to descend, colloidal particles, and when the appropriate coagulating agents are selected, dissolved contaminants typical of a given industry can also be removed. In a practice, coagulation is carried out by introducing metal ions into the sewage, most commonly iron and aluminium, which undergo hydrolysis leading to the formation of sludge flocs. These destabilize the colloids present in sewage and can also adsorb other dissolved or hardly soluble contaminants. Coagulation is most often carried out by dosing suitably selected sulphates and/or iron/aluminium chlorides. Another method that does not require the addition of salting compounds to the treated wastewater is electrocoagulation, involving the direct introduction of aluminium or iron ions, which are generated in situ by electrolytic oxidation of metal electrodes. Recently, the electrocoagulation process has been successfully used to handle a variety of types of industrial wastewater, such as textile wastewater [15], $\mathrm{Cu}$ production process wastewater [16] and paint manufacturing wastewater [17]. This is because electrocoagulation, as an industrial wastewater purification method, has many benefits related to its simplicity and ease, especially the fact that it reduces wastewater treatment costs.

Regardless of the method of feeding the coagulant or using other treatment methods on coking wastewater, deposits formed during the treatment of the coke wastewater are a substantial problem. At present, post-coagulation sediments, after dehydration and mixing together with excessive biological and other sludge, are directed along with the coal charge to coke oven batteries, in the case of plants with a sludge management system. In cases where such a system is absent, the sludge is directed to the sewerage network of a company providing services in the field of wastewater disposal and treatment through appropriate permits.

The short overview presented here shows that there is a growing interest in the use of naturally occurring or wastederived oxygen carrier materials for power generation purposes. In the light of the multiple aspects of interest, such as attractive low cost and high availability, it would be desirable to identify a suitable candidate for the CLC process. Encouraging reactivity results have been reported in the literature for waste- or natural raw materials-based OCs containing some iron species. For this reason, powders obtained from electrocoagulation of coking plant wastewater could potentially be considered for use in CLC.

Nevertheless, no practical use of the wastes obtained from coking plant wastewater has yet been reported. It would be economically sound to use these as oxygen carriers rather than synthetic materials obtained from pure chemicals. This might be especially attractive in the light of the limited OC lifetime and possible losses during circulation in CLC reactor systems.

In this regard, the present paper aims to determine new sources of oxygen carriers for energy generation applications (patent application submitted). Therefore, different sludge samples from coke oven wastewater treatment processes were synthesized. The powders were composed mainly of ferric/ferrous-based solids and were calcined at high temperatures in contact with air. The resulting fine powders were mostly composed of iron (III) oxide. These materials were subjected to multicycle redox reactivity tests carried out via thermogravimetric analysis (TG). The effects of material preparation conditions and process temperature on the redox reaction rates were examined. In addition, fundamental parameters such as oxygen transport capacity and chemical stability were tested. These parameters, together with beneficial amounts of active metal 
oxide (Fe species, supported by ICP-OES) and good thermal stability (high-temperature oven with IR camera), proved their oxygen carrier potential.

\section{Experimental}

\section{Preparation of raw samples}

The raw powder samples were prepared using electrocoagulation of real wastewater from a coking plant and model wastewater. Therefore, different sludge samples from the coking process were synthesized. The EC runs were conducted at a temperature of $25^{\circ} \mathrm{C}$, and $0.5 \mathrm{~L}$ of samples of sludge water was electrocoagulated by applying iron electrodes (in the form of $5 \times 3 \mathrm{~cm}$ discs) in a 1-L glass vessel. The electrode pair was immersed in the wastewater to a depth of $10 \mathrm{~cm}$ with the electrodes separated by approximately $1 \mathrm{~cm}$. During the preparation stage, multiple configurations were used for electrocoagulation, to study the effect of the wastewater treatment wastes on the properties of the final oxygen carrier product. Various conditions, such as ion current and voltage, duration of electrocoagulation process, stirring rate of wastewater solution and aeration/non-aeration of the wastewater solution, were analysed.

At the cathode, water was reduced to gaseous hydrogen and hydroxyl anions, while at the anode Fe metal was oxidized to the cations $\mathrm{Fe}^{2+} / \mathrm{Fe}^{3+}$. Therefore, hydrogen bubbles were produced at the anode, while oxygen bubbles were produced on the cathode surface. Then, during electrochemical synthesis, a consistent progressive surface coverage by ferric oxyhydroxide particles was observed. In the course of the process, reddish brown fluff was produced in the solution. The resulting precipitate was filtered using a paper filter. Prior to the reactivity study, the solid samples were subjected to overnight drying at room temperature, followed by a drying process of $3 \mathrm{~h}$ at $105{ }^{\circ} \mathrm{C}$ in a chamber dryer. The obtained powders were:

- Calcined at high temperatures with flowing air in the oven for $3 \mathrm{~h}$ at $850{ }^{\circ} \mathrm{C}$.

- Directly introduced to TG and heated in the TG chamber for $30 \mathrm{~min}$ at $850{ }^{\circ} \mathrm{C}$.

- Not calcined.

Thermal treatment was used to increase the strength of the particles and to remove organic matter. The solid material was ground in an agate mortar. The calcined samples were fine powders, brownish-red-black in colour due to the iron species present.

\section{Sample Group I}

The collected coke oven wastewater treatment plant samples from the $\mathrm{O}$ coking plant were subjected to a 15 -min electrocoagulation process with $0.5 \mathrm{~L}$ of wastewater at a voltage of $5 \mathrm{~V}$ and a current of $0.43 \mathrm{~A}$. In total, $2 \mathrm{~L}$ of this wastewater was treated by the electrocoagulation process. The resulting precipitate was filtered using a hard paper filter and dried overnight at room temperature. Then, it was dried in a chamber dryer at $105^{\circ} \mathrm{C}$ for $1 \mathrm{~h}$. As a result, powder material was obtained in the form of dark brown flakes. The powder material was divided into two parts. One part was subjected to an additional operation consisting of calcination in an oven with flowing air at $850{ }^{\circ} \mathrm{C}$ for $3 \mathrm{~h}$. After calcination, a mass loss was detected (40.67 mass\%), and the sample colour had changed to brick red. Both materials were ground in an agate mortar and subjected to reactivity tests. The samples were labelled "O calcined" and "O non-calcined".

\section{Sample Group II}

For purposes of comparing the behaviour of potential oxygen carriers made from raw waste material, model wastewater was also prepared from pure chemicals. The procedure for model wastewater preparation has been described elsewhere [18]. A solid was produced from this solution in a similar manner as for real industrial wastewaters (coke oven wastewaters) and was then subjected to further examination.

\section{Sample Group III}

The three samples from coke oven wastewater treatment plant A were analysed. Samples were labelled as follows: 1. “AMO1-4, EKG 5 V O2 mix", 2. "AMO1-4, EKG 5 V mix + EKG 5 VO2 mix" and 3. "AMO1-4, EKG $5 \mathrm{~V}$ $\mathrm{O} 2+$ EKG 5V mix". Sample 1 was obtained by electrocoagulation of $0.5 \mathrm{~L}$ of sludge water for $15 \mathrm{~min}$ with a voltage of $5 \mathrm{~V}$, using mixing of the sludge water followed by aeration for a 15-min period. Sample 2, namely AMO14, EKG $5 \mathrm{~V}$ mix + EKG $5 \mathrm{VO} 2$, mix, was obtained in two stages. The first stage was electrocoagulation of $0.5 \mathrm{~L}$ of sludge water at $5 \mathrm{~V}$, using mixing of the sludge water for $15 \mathrm{~min}$. Then, the process was switched to the second stage of electrocoagulation with the application of $5 \mathrm{~V}$ with aeration of the wastewater, also for $15 \mathrm{~min}$. Sample 3, namely AMO1-4, EKG $5 \mathrm{~V} \mathrm{O} \mathrm{O}_{2}+\mathrm{EKG} 5 \mathrm{~V}$ mix, was obtained in two stages. The first stage was electrocoagulation of $0.5 \mathrm{~L}$ of sludge water at $5 \mathrm{~V}$ with aeration of the wastewater for $15 \mathrm{~min}$. Then, the process was switched to the second stage of electrocoagulation of $5 \mathrm{~V}$ with 
continuous mixing of the wastewater using a magnetic stirrer. Finally, the resulting precipitates were filtered and dried as described above.

\section{Instrumentation}

\section{Basic characterization}

The chemical composition of the samples was determined by inductively coupled plasma optical emission spectrometry (ICP-OES), using a Thermo Scientific iCAP 6500 instrument.

The pelletized samples $(5 \times 3 \mathrm{~mm})$ were placed in an oven (PR 25/1750/PIE) and heated up to $1650{ }^{\circ} \mathrm{C}$ to observe their melting behaviour. The average shrinkage, deformation, hemisphere (melting) and flow temperatures were determined using an HT camera to observe the changes in pellet shape during the heating process. Those standardized accredited measurements were repeated at least twice for each sample.

The microstructure of the material surface was studied using scanning electron microscopy (SEM), using a JEOL JSM-6610 LV instrument with an energy-dispersive X-ray spectrometer (EDS) for chemical micro-analysis purposes. The EDS with an $\mathrm{Si}(\mathrm{Li}) \mathrm{X}$-ray detector was used for the investigation of the homogeneity of the samples.

The surface morphology was studied by gluing carbon tape onto the samples; carbon tape was not used in the chemical analysis of the samples. The study was conducted using a low vacuum detector at an accelerating voltage of $15 \mathrm{kV}$.

The X-ray diffraction (XRD) patterns of the sewage sludge ashes were obtained using a high-resolution PANalytical Empyrean diffractometer with $\mathrm{Cu} \mathrm{K}_{\alpha}$ radiation $(40 \mathrm{kV}, 30 \mathrm{~mA})$ equipped with a PIXcel detector. The diffraction patterns were collected using a $2 \Theta$ scan from 5 to $90^{\circ}$ with $0.0131^{\circ}$ steps. The data analysis was carried out using HighScore Plus software supplied by PANalytical. The software was used for both qualitative and quantitative analyses. The ICDD PDF-4 database was used to identify the phases. The reference intensity ratio (RIR) technique described in detail elsewhere [19] was applied for the quantitative analysis. This means that the strongest peaks for each phase were applied for calculations, while corresponding ratios were taken from the ICDD PDF-4 database, together with RIR values. In this method, corundum was used as the reference.

\section{Thermogravimetric analysis (TG)}

Thermogravimetric experiments were conducted using a thermal analyser (STA 409 PG Luxx by Netzsch) which was coupled with a QMS 403C by Aëolos. The mass spectrometer used for the evolved gas analysis could detect mass numbers of 1-300 amu in the SCAN or MID mode. In the experiments, the mass changes in the metal oxide oxygen carriers were measured isothermally as a function of time. The sample was heated in an inert Ar atmosphere with a heating rate of $10 \mathrm{~K} \mathrm{~min}^{-1}$. When a temperature of $700{ }^{\circ} \mathrm{C}$ was reached, the sample was held for about $5 \mathrm{~min}$ and then the experiment was started, with consecutive introduction of reducing and oxidizing gases. Three reduction/oxidation cycles were conducted at atmospheric pressure to determine the reactivity and oxygen carrier stability. One experiment took over 700 min. Furthermore, the thermal stability of fresh material obtained from wastewater sediments from the coking process by electrocoagulation and chemical coagulation was also analysed via TG. The sample was heated in an inert atmosphere from room temperature to $1000{ }^{\circ} \mathrm{C}$, with a heating rate of $10 \mathrm{~K} \mathrm{~min}^{-1}$, enabling quantification of both water and organic matter content.

In the CLC measurements, a sample weighing approximately $5 \mathrm{mg}$ was placed on an $\mathrm{Al}_{2} \mathrm{O}_{3}$ plate. A mixture of $3 \% \mathrm{H}_{2} / \mathrm{Ar}$ (used as a fuel agent) was used for the reduction reaction, and $20 \% \mathrm{O}_{2} / \mathrm{N}_{2}$ was used for the oxidation reaction. The reaction gas flow rates were set at $125 \mathrm{~mL} \mathrm{~min}^{-1}$. The reduction time was set at $15 \mathrm{~min}$, and the oxidation time was set at $5 \mathrm{~min}$. To avoid the reduction gases mixing with air, the TG system was flushed with Ar for $5 \mathrm{~min}$ before and after each reduction/oxidation reaction. To investigate the temperature effect, redox cyclic tests were carried out in the temperature range $700-950{ }^{\circ} \mathrm{C}$.

Hydrogen is an environmentally friendly energy carrier derived from, for example, solar or biomass, or from coal. Because hydrogen, which is part of synthesis gas, can be used as gaseous fuel for CLC for power generation, the possible utilization of novel sources of raw materials for OC synthesis was investigated in this work. Hydrogen was used as a fuel in this study since it is the major component of syngas from biomass/coal gasification processes. Another reason for using $\mathrm{H}_{2}$ was to explore the oxygen transfer capacity of the materials under very severe reducing conditions, i.e. under $\mathrm{H}_{2}$.

The fractional conversions (i.e. the fractional reduction and the fractional oxidation) were calculated from the TG data. The fractional conversion $(X)$ is defined by following equations:

Fractional reduction: $X=\frac{M_{\mathrm{oxd}}-M}{M_{\mathrm{oxd}}-M_{\mathrm{red}}}$

Fractional oxidation: $X=\frac{M-M_{\mathrm{red}}}{M_{\mathrm{oxd}}-M_{\mathrm{red}}}$. 
For the hydrogen cyclic CLC measurements, $M$ denotes the instantaneous mass, $M_{\text {oxd }}$ denotes the mass of a completely oxidized sample in the TG experiment (i.e. the maximum mass after oxidation) and $M_{\text {red }}$ denotes the mass of a completely reduced sample in the TG experiment (i.e. the minimum mass after reduction). The reaction rates were calculated by differentiating the mass data with respect to time.

\section{Results and discussion}

\section{Material characterization}

\section{Chemical composition and thermal resistivity}

The chemical composition of the samples was determined by ICP-OES. This showed that they were mainly composed of iron species with $43.17-45.88$ mass $\%$ of Fe content, together with inert compounds containing silica and alumina species, at 0.14-0.39 mass \% and 0.02-0.04 mass\%, respectively. In addition, some alkaline compounds, such as calcium and magnesium compounds, containing specifically $0.09-0.66$ mass $\%$ of $\mathrm{Ca}$ and $0.02-0.67$ mass $\%$ of $\mathrm{Mg}$, were detected.

The melting points are known to be the important parameters in evaluating the agglomeration tendencies of oxygen carriers. Furthermore, some loss of reactivity might be expected as a result of low melting temperature, which is the reason the melting behaviour was examined in this paper. Consequently, the valuation of thermal behaviour confirmed the high-temperature resistivity of the obtained powders, with melting temperatures reaching as high as $1320{ }^{\circ} \mathrm{C}$ at least. This resistivity obtained should be sufficient for these compounds to be used in CLC processes.

\section{Phase composition data}

The phase composition for fresh and reacted sewage samples obtained from the $\mathrm{O}$ coking oven wastewater plant is shown in Table 1 . This contains both qualitative and quantitative analyses data of the species based on obtained XRD patterns. An applied methodology was described in "Instrumentation" section.

The analysis of powder samples from group I shows that fresh and unreacted samples contain mainly various forms of iron species: $\mathrm{FeO}(\mathrm{OH}), \mathrm{Fe}_{4}\left(\mathrm{Fe}(\mathrm{CN})_{6}\right)_{3}, \mathrm{Fe}_{2} \mathrm{O}_{3}$ maghemite/ $\mathrm{Fe}_{3} \mathrm{O}_{4}$ magnetite and $\mathrm{Fe}_{2} \mathrm{O}_{3}$ haematite, together with $\mathrm{NaOOH}$. However, it was difficult to carry out the analysis for this sample due to the broader peaks present in the X-ray powder diffract gram, as shown in Fig. 1.

The fresh powder sample was calcined in a high-temperature oven at $850{ }^{\circ} \mathrm{C}$ in air flow, possibly to increase its mechanical strength and to release the organic ballast, i.e. any organic matter, which is not needed in the CLC process. Thermal treatment of the sewage sample showed that it was mainly composed of haematite $\mathrm{Fe}_{2} \mathrm{O}_{3}$, with very little $(1 \%)$ of minor phases such as $\mathrm{KCl}, \mathrm{CaS}, \mathrm{CaCO}_{3}$, $\mathrm{SiO}_{2}$, clinochlore and $\mathrm{NaCl}$ (Table 1). It is desirable that OC does not react/suffer from the possible impurities, both from the fuel and OC itself. The impurities involved in an interaction with the OC material and their potential harms should be considered in the view of their practical application in energy sector [8]. It is also known that Fe-based OCs are relatively resistant to poisoning. Their interaction with impurities is minimal within the temperature range of the CLC process and was shown in some papers [4, 21].

Furthermore, the solid sample has a well-crystallized form compared to that of non-thermally treated samples (Fig. 1). Next, the fresh $\mathrm{O}$ sample was reacted using $\mathrm{TG}$ at temperatures of $700-950{ }^{\circ} \mathrm{C}$. As a result of application in the CLC process, XRD data indicated that the sample was composed of simple iron species, namely $\mathrm{Fe}_{2} \mathrm{O}_{3}(79 \%)$, $\mathrm{Fe}_{3} \mathrm{O}_{4}(10 \%), \mathrm{FeO}(1 \%)$ and metallic $\mathrm{Fe}(6 \%)$, instead of the previously observed $\mathrm{FeO}(\mathrm{OH})$ or $\mathrm{Fe}_{4}\left(\mathrm{Fe}(\mathrm{CN})_{6}\right)_{3}$ species (Fig. 1). This means that the fresh sample has been significantly transformed during the redox reactions in the TG chamber.

Table 2 shows XRD data obtained for sewage synthesized from model wastewater. Here, in contrast to real

Table 1 Quantitative and qualitative XRD data for $\mathrm{O}$ fresh and reacted sewage

\begin{tabular}{|c|c|c|c|c|c|}
\hline \multirow{2}{*}{$\begin{array}{l}\text { Sample } \\
\text { Fresh unreacted O. Sewage made from real coke oven } \\
\text { wastewater }\end{array}$} & \multicolumn{4}{|c|}{ Main phases $/ \%$} & \multirow{2}{*}{ Minor phases $/ \%$} \\
\hline & $\mathrm{FeO}(\mathrm{OH})$ & $\mathrm{Fe}_{4}\left(\mathrm{Fe}(\mathrm{CN})_{6}\right)_{3}$ & $\mathrm{NaOOH}$ & $\begin{array}{r}\mathrm{Fe}_{2} \mathrm{O}_{3} \\
\mathrm{Fe}_{3} \mathrm{O}_{4}\end{array}$ & \\
\hline & * & * & $*$ & $*$ & - \\
\hline \multirow[t]{2}{*}{$\begin{array}{l}\text { Calcined in air unreacted O. Sewage made from real } \\
\text { coke oven wastewater }\end{array}$} & $\mathrm{Fe}_{2} \mathrm{O}_{3}$ & $\mathrm{Fe}_{3} \mathrm{O}_{4}$ & $\mathrm{FeO}$ & $\mathrm{Fe}$ & $\begin{array}{l}\mathrm{KCl}, \mathrm{CaS}, \mathrm{CaCO}_{3}, \mathrm{SiO}_{2}, \\
\text { clinochlore, } \mathrm{NaCl}\end{array}$ \\
\hline & 99 & - & - & - & 1 \\
\hline $\begin{array}{l}\text { TG reacted O. Sewage made from real coke oven } \\
\text { wastewater }\end{array}$ & 79 & 10 & 1 & 6 & 4 \\
\hline
\end{tabular}

*Problematic to determine the amount 
Fig. 1 XRD identification of phases of sewage samples obtained from coke oven wastewater. a Fresh. b Fresh calcined and $\mathbf{c}$ Reacted in TG

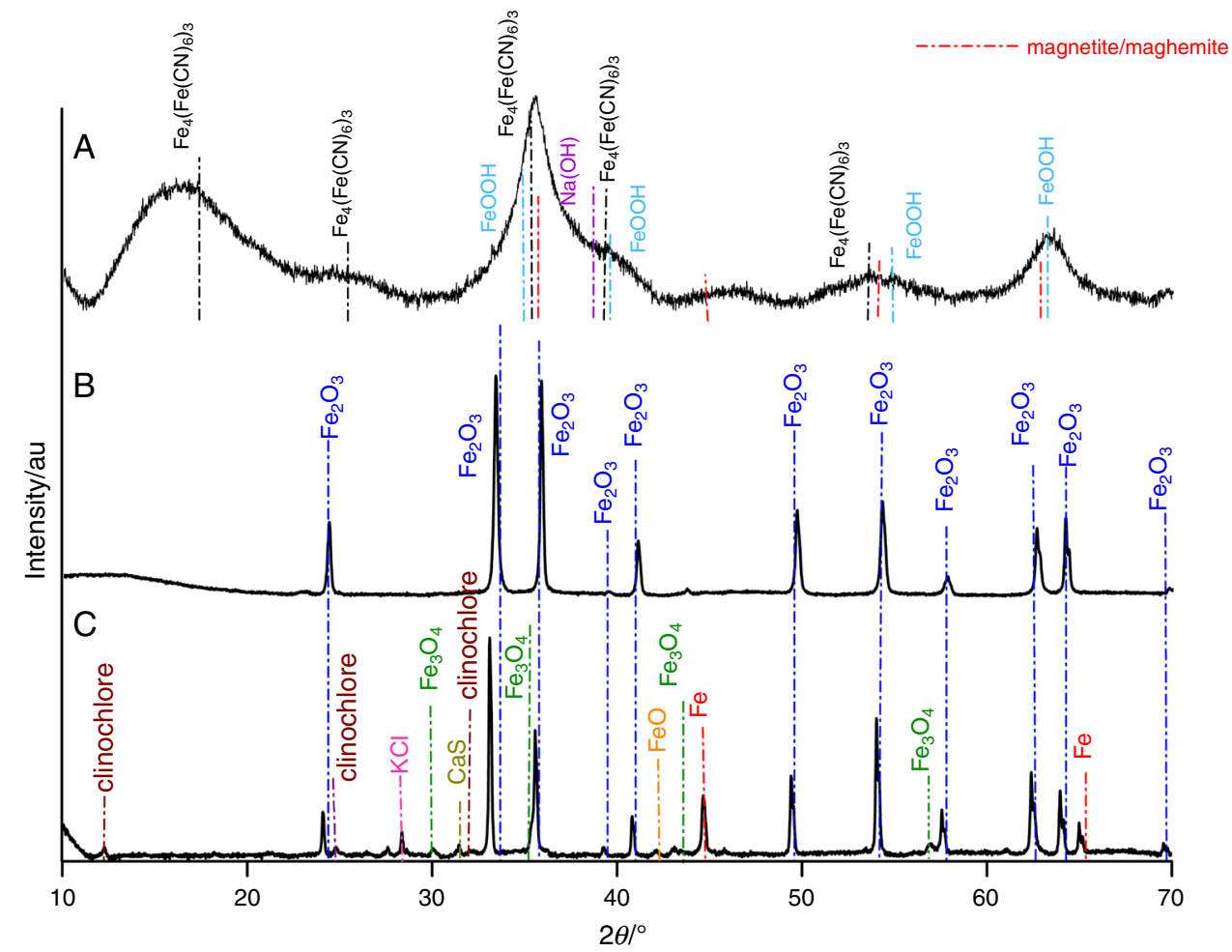

Table 2 Quantitative and qualitative XRD data for sewage from model wastewater

\begin{tabular}{|c|c|c|c|c|c|}
\hline \multirow[t]{2}{*}{ Sample } & \multicolumn{4}{|c|}{ Main phases $/ \%$} & \multirow{2}{*}{$\begin{array}{l}\text { Minor phases/\% } \\
\mathrm{KCl}, \mathrm{CaS}, \mathrm{CaCO}_{3}, \mathrm{SiO}_{2} \text {, clinochlore, } \mathrm{NaCl}\end{array}$} \\
\hline & $\mathrm{Fe}_{2} \mathrm{O}_{3}$ & $\mathrm{Fe}_{3} \mathrm{O}_{4}$ & $\mathrm{FeO}$ & $\mathrm{Fe}$ & \\
\hline Fresh sewage from model coke oven wastewater & 93 & 4 & - & $<1$ & 3 \\
\hline Calcined in air unreacted sewage from model coke oven wastewater & 78 & 11 & 2 & 3 & 6 \\
\hline TG reacted sewage from model coke oven wastewater & 74 & 11 & 4 & 6 & 5 \\
\hline
\end{tabular}

wastewater sewage samples, the fresh samples are composed of different iron oxides and $\mathrm{Fe}^{0}$. The fresh sample contains as much as $93 \%$ haematite and some magnetite (4\%). The thermal treatment in an HT oven and the TG chamber showed that other forms of iron oxide might also be present (Fig. 2). This behaviour means that lower-oxidation-state oxides may lead to lower oxygen transport capacity when used as oxygen carrier material for CLC processes. This performance will be evaluated during the TG examinations.

The XRD data (not shown) for the fresh AMO1-4, EKG $5 \mathrm{~V}$ mix + EKG $5 \mathrm{VO}_{2}$, mix sample indicated the presence of the following compounds: $\gamma-\mathrm{FeOOH}$, which is iron oxyhydroxide, specifically lepidocrocite, $\mathrm{Fe}_{4}\left(\mathrm{Fe}(\mathrm{CN})_{6}\right)_{3}$ (Prussian blue) and $\mathrm{NaCN}$ (sodium cyanide). This composition is similar to that obtained for the AMO1-4, EKG $5 \mathrm{~V} \mathrm{O}_{2}+$ EKG $5 \mathrm{~V}$ mix sample, which was specifically $\gamma$ FeOOH and $\mathrm{Fe}_{4}\left(\mathrm{Fe}(\mathrm{CN})_{6}\right)_{3}$, but instead of $\mathrm{NaCN}$ some $\mathrm{SO}_{3}$ was present. This correlates well with ICP-OES data supporting the presence of valuable Fe species, which might be useful for the CLC process.

The compound $\gamma-\mathrm{FeOOH}$ is an example of iron oxide called lepidocrocite (either esmeraldite or hydrohaematite) which is a mineral commonly found in iron ore deposits or in the form of a rust scale inside steel water pipes. It is usually yellow or dark red-orange. Lepidocrocite is an example of an iron oxide and has been extensively used for removing heavy metal ions such as $\mathrm{Cr}$ (VI) and As(IV) [20] from metallurgic or wood products. Iron hydroxide compounds (goethite, lepidocrocite) occur under reducing and weakly acidic to weakly alkaline conditions, as intermediate phases in the formation of Fe oxides. The mechanism of $\gamma-\mathrm{FeOOH}$ formation is assumed to be $\mathrm{Fe}^{2+}+2 \mathrm{H}_{2}$ $\mathrm{O} \leftrightarrow \mathrm{FeOOH}+3 \mathrm{H}^{+}+1 \mathrm{e}^{-}$. However, small variations in operating conditions such as $\mathrm{pH}$, stirring method, temperature and pressure could lead to one or several species in aqueous solution. This is the reason for observing lepidocrocite among other iron species in the solid samples obtained here. 
Fig. 2 XRD identification of phases of sewage samples obtained from model coke oven wastewater $\mathbf{a}$ fresh, b reacted in $\mathrm{TG}$ and $\mathbf{c}$ fresh calcined

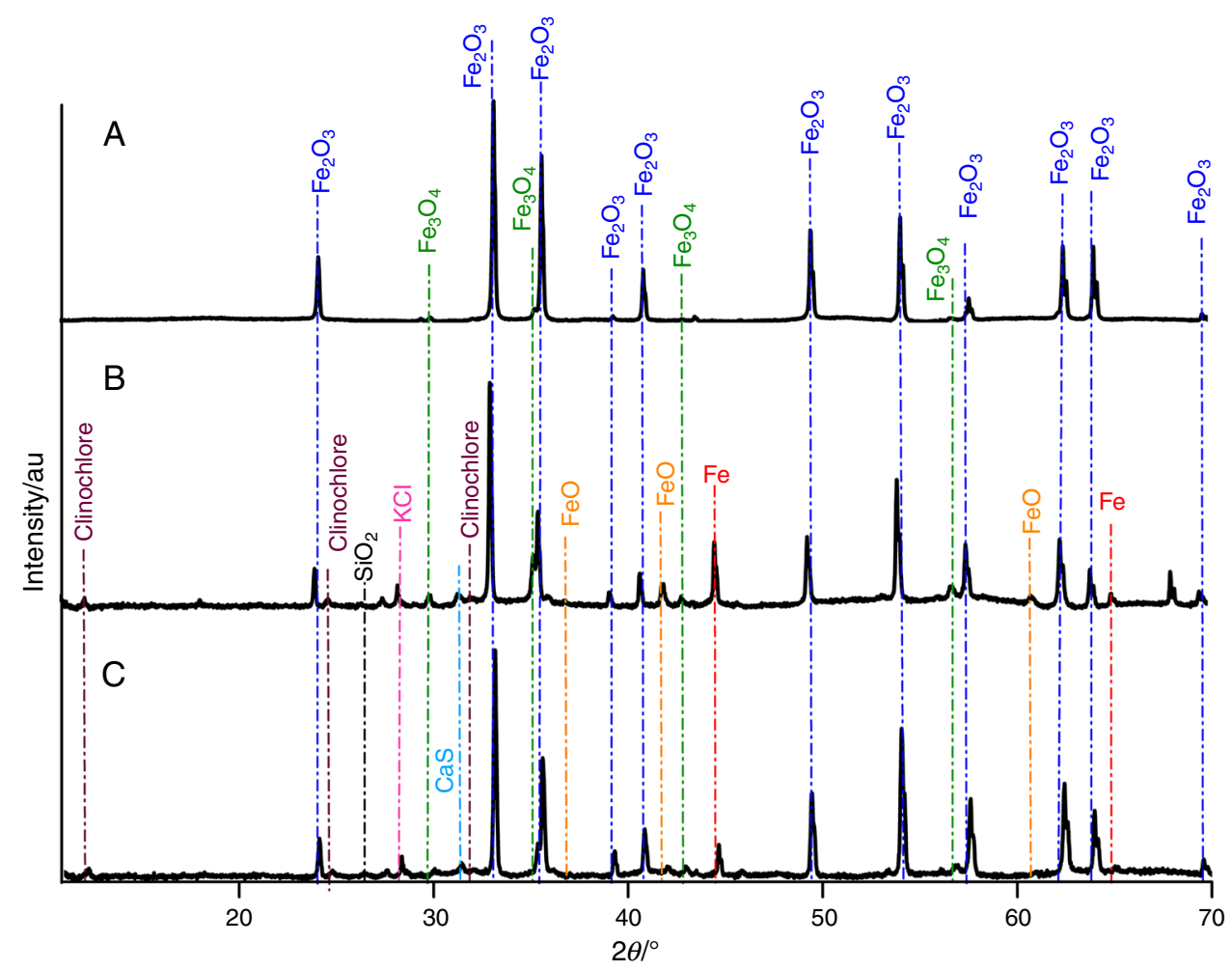

Prussian blue (also referred to as PB) is a solid blue material, practically insoluble in water. This ferric ferrocyanide is also called Berlin, Chinese or Paris blue. PB has been used extensively as a pigment for centuries. Prussian blue is strongly coloured and tends towards black and dark blue, which is associated with the energy of the transfer of electrons $\mathrm{Fe}(\mathrm{II})-\mathrm{Fe}(\mathrm{III})$. It is used as a histopathology stain in pathology testing. PB is also known as an antidote for radioactive poisoning and is used in dyes, inks and cosmetics [22]. The mechanism of Prussian blue formation is as follows:

$$
\begin{aligned}
& \mathrm{Fe}^{2+}+6 \mathrm{CN}^{-}+1 / 4 \mathrm{O}_{2}+\mathrm{H}^{+} \rightarrow \mathrm{Fe}(\mathrm{CN})_{6}^{3-}+1 / 2 \mathrm{H}_{2} \mathrm{O} \\
& 4 \mathrm{Fe}^{2+}+\mathrm{Fe}(\mathrm{CN})_{6}^{3-}+1 / 4 \mathrm{O}_{2}+3 \mathrm{H}^{+} \\
& \quad \rightarrow 3 \mathrm{Fe}(\mathrm{CN})+\mathrm{Fe}_{4}\left[\mathrm{Fe}(\mathrm{CN})_{6}\right]_{3}+1 /{ }_{2} \mathrm{H}_{2} \mathrm{O}
\end{aligned}
$$

In the reacted samples of group III, the same compounds are observed as in the fresh samples. However, the intensities of the XRD peaks are different, proving that the proportions of the compounds have changed. This means that in samples reacted during CLC cycling, the relative amounts of $\mathrm{Fe}_{4}\left(\mathrm{Fe}(\mathrm{CN})_{6}\right)_{3}$ and $\gamma$-FeOOH have changed. During the redox reactions, $\gamma-\mathrm{FeOOH}$ significantly decreased, while the amount of $\mathrm{Fe}_{4}\left(\mathrm{Fe}(\mathrm{CN})_{6}\right)_{3}$ doubled. In both the reacted samples, well-crystallized $\mathrm{SiO}_{2}$ was detected. $\mathrm{SiO}_{2}$ was not observed in the fresh solid samples, and the reason for that is not clear. It may be that it was present in amorphous form, which transformed to a crystalline form after processing at high temperatures and was therefore detectable by X-rays.

Phase composition analysis of fresh samples showed that in the AMO1-4, EKG $5 \mathrm{~V} \mathrm{O}_{2}+\mathrm{EKG} 5 \mathrm{~V}$ mix sample, significant amounts of $\mathrm{SO}_{3}$ were detected, which correlates well with ICP-OES data. The reactions in the TG chamber caused removal of $\mathrm{SO}_{3}$ from the solid sample when high process temperatures were applied.

\section{Reactivity tests using TG}

A successful oxygen carrier must meet the expectations described above during the course of reduction and oxidation cycles at high temperatures in a CLC power plant. Therefore, reactivity tests were carried out via TG. Figure 3 shows the results of thermogravimetric analysis of the powdered samples obtained by electrocoagulation of wastewater from the $\mathrm{O}$ coking plant, up to $1000{ }^{\circ} \mathrm{C}$. This answers the question about thermal stability. The two sample variants described above were analysed. In the case of the calcined sample "O calcined", a small stable mass loss was observed, which amounted to approximately 2.4 mass $\%$. In the second variant, an intensive multistage process of sample decomposition was observed. The analysis of the mass loss indicates four clearly separated stages: A, B, C and D. The first stage (A) ends when the sample is heated to $55{ }^{\circ} \mathrm{C}$, and the loss in mass is $1.6 \%$. This behaviour is associated with sample drying and 
(a)

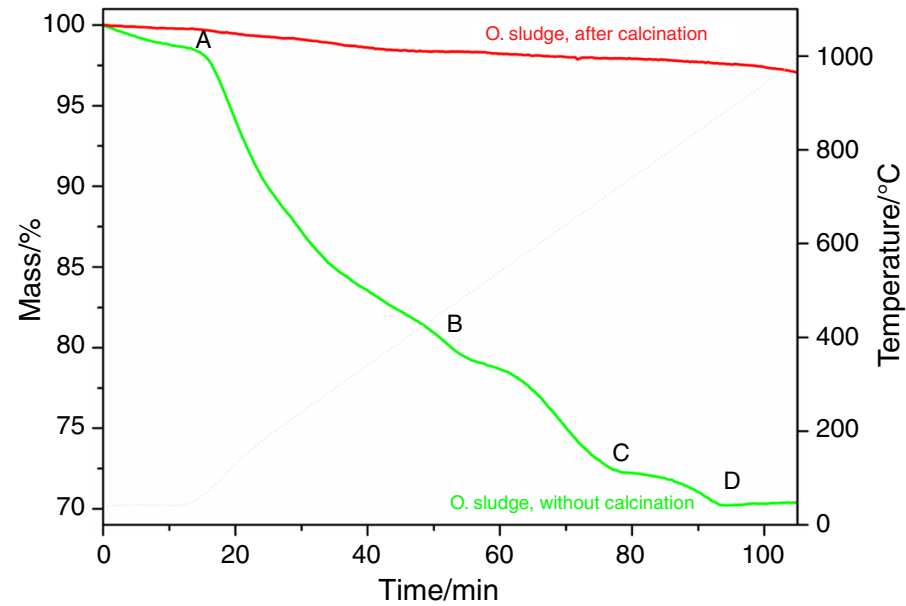

(b)

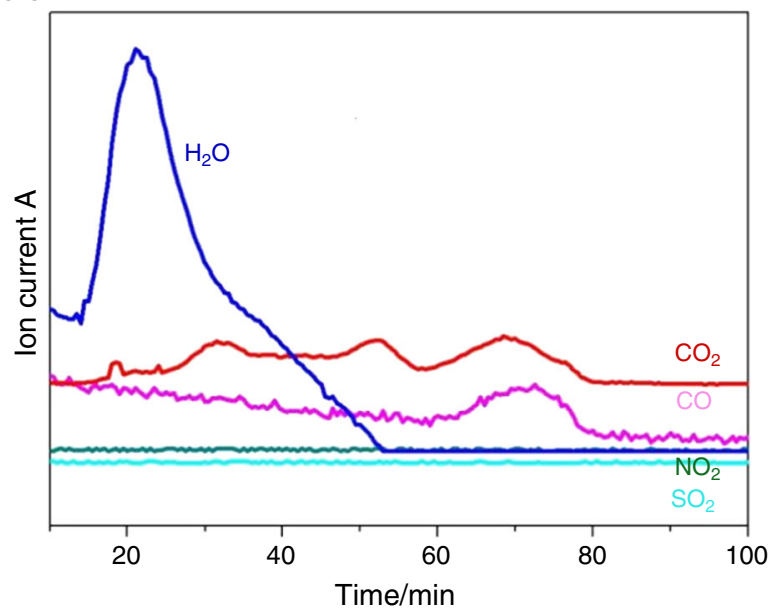

Fig. 3 Thermogravimetric stability analysis of the sludge obtained as a result of electrocoagulation of wastewater from the O coking plant (a), MS data (b)

removal of humidity from the sample surface, as the MS study shown in Fig. 3b demonstrates. Stage B ends when the temperature reaches $482{ }^{\circ} \mathrm{C}$, with a mass loss of approximately $18.8 \%$. This mass change is due to removal of the water bound in the material structure. In other words, structural transformations from $\gamma$-FeOOH through magnetite $\left(\gamma-\mathrm{Fe}_{2} \mathrm{O}_{3}\right)$ and finally to $\alpha-\mathrm{Fe}_{2} \mathrm{O}_{3}$ took place. This structural transformation has been studied previously in detail elsewhere [23], showing initial changes at $175^{\circ} \mathrm{C}$ which were completed at $\sim 300{ }^{\circ} \mathrm{C}$ for the first conversion, while the conversion of $\gamma-\mathrm{Fe}_{2} \mathrm{O}_{3}$ to $\alpha-\mathrm{Fe}_{2} \mathrm{O}_{3}$ was observed at $\sim 500{ }^{\circ} \mathrm{C}$.

The next mass loss of $6.9 \%$, in stage $\mathrm{C}$, is observed at $704{ }^{\circ} \mathrm{C}$. This behaviour is attributed to loss of organic matter from the sample. The last stage of the sludge sample decomposition takes place at a temperature of $873{ }^{\circ} \mathrm{C}$ and corresponds to a $2.3 \%$ mass loss.

The observed behaviour shows that to obtain a stable sewage material from wastewater some calcination is required as pretreatment step. Next, the samples were tested using TG to obtain data on their reactivity and their possible application as oxygen carrier materials. For this reason, redox cycling examination was carried out at 700-950 ${ }^{\circ} \mathrm{C}$, as shown in Fig. 4. For comparison purposes, a model wastewater sludge was also prepared.

Reactivity data clearly show that the calcined O sample is reactive both with fuel and with oxygen during reduction and oxidation reactions. The cycling performance is good, evaluated based on the observed mass decreases and increases. In addition, a reference material shows that it is reactive. However, the TG curves differ in terms of both the amount of oxygen delivered to the fuel and the shape of the curves.
To discuss the redox performance, a close look at the oxygen capacity parameter is required. Accordingly, Fig. 5 shows the comparison of oxygen capacities calculated as a function of cycle number and temperature.

At temperatures as low as $700{ }^{\circ} \mathrm{C}$, the mean value of oxygen capacity for three reduction cycles is 26.53 mass $\%$, while for the synthetic sample it is lower. Increasing the CLC process temperature to $800{ }^{\circ} \mathrm{C}$ leads to an increase in capacity to approximately 27.96 mass $\%$. This means that more oxygen is available for the fuel. A further increase in temperature, i.e. to $850{ }^{\circ} \mathrm{C}$, leads to a 27.27 mass $\%$ change, while for $900{ }^{\circ} \mathrm{C}$ and $950{ }^{\circ} \mathrm{C}$ the change is 25.43 and 22.35 mass $\%$, respectively. When compared to the model wastewater sludge, it is evident that the natural sample can deliver more oxygen. Furthermore, in both cases some decrease in reactivity is observed. This is common behaviour for iron species in CLC processes, due to their agglomeration tendency and difficulties in the regeneration. However, this behaviour is observed more clearly for the natural sample. The explanation for this behaviour may be the presence of impurities which help to stabilize the structure of the natural material (Table 1) $[8,21]$. Based on the data shown, it can be concluded that the optimal temperature range for the CLC fuel combustion process for oxygen carriers made from coke oven wastewater is $800-900{ }^{\circ} \mathrm{C}$.

Next, both reduction and oxidation rates were calculated by differentiating the mass data with respect to time. As a result, the comparisons of reduction and oxidation rates calculated at $700{ }^{\circ} \mathrm{C}$ for $\mathrm{O}$ wastewater sludge and model wastewater sludge are shown in Fig. $6 a$ and b. The analysis of the rates shows that for the first reduction cycle, the rate is $\quad 3.93$ mass $\% \min ^{-1} \quad$ (maximum rate) and 1.27 mass $\% \mathrm{~min}^{-1}$ for $\mathrm{O}$ wastewater sludge and model 
Fig. 4 Comparison of the test results of thermogravimetric cyclic analysis of sludge from coking plant $\mathrm{O}$ wastewater and from synthetic coke oven wastewater

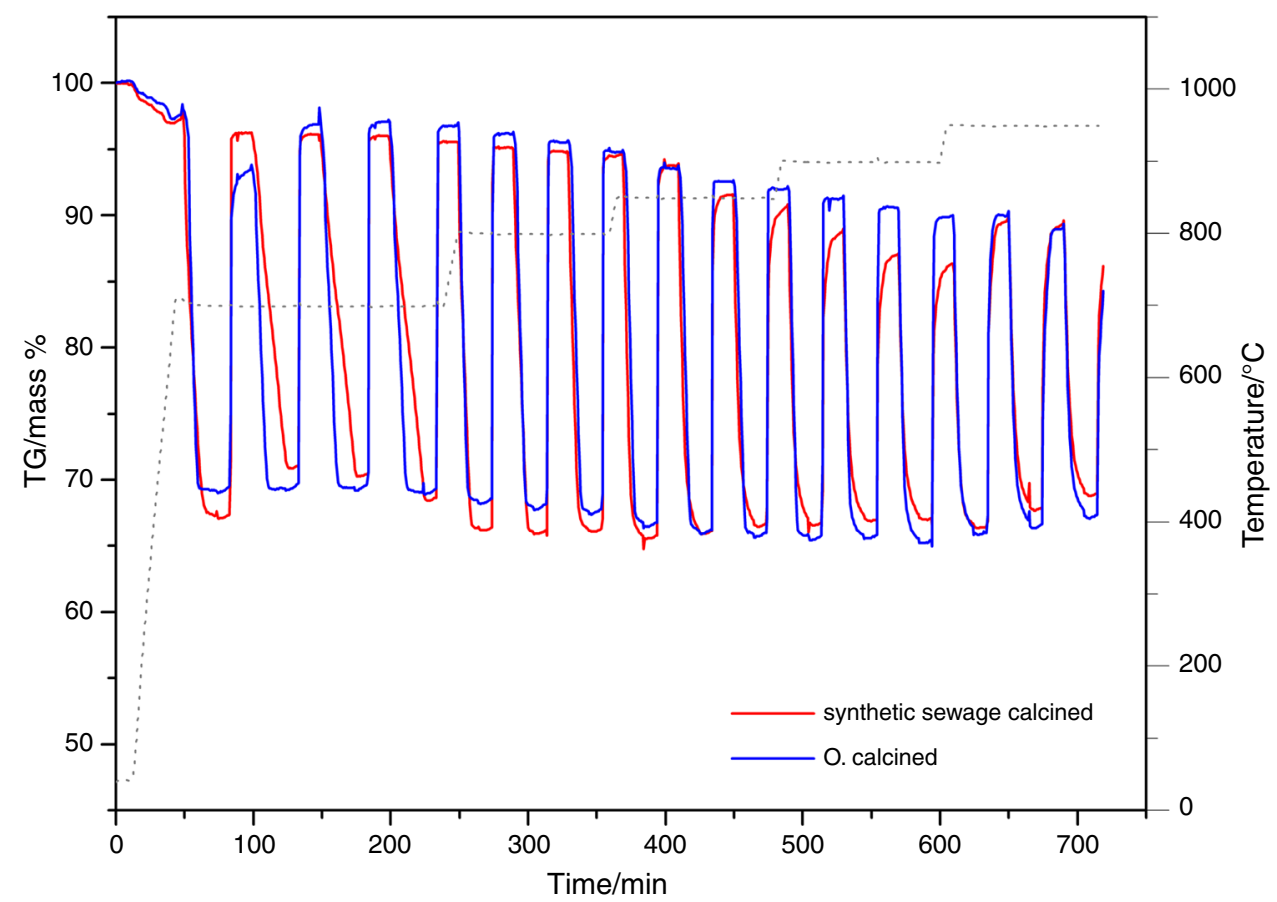

wastewater sludge, respectively. Furthermore, two maxima are observed for reduction in the former material (3.93 $\operatorname{mass} \% \mathrm{~min}^{-1}$ and 2.56 mass $\% \mathrm{~min}^{-1}$ ), while the second cycle shows the same stable rate over the whole reduction process. This behaviour means that the two samples differ in terms of their chemical nature. The two reduction stages are due to the different forms of iron species present. XRD data for calcined samples of $\mathrm{O}$ sediment and calcined sludge from synthetic coke oven wastewater revealed that the former material was mainly composed of $\mathrm{Fe}_{2} \mathrm{O}_{3}$ (99\%), whereas the latter was composed of different iron oxide forms. It also contained mostly haematite $\mathrm{Fe}_{2} \mathrm{O}_{3}(78 \%), 11 \%$ of magnetite $\mathrm{Fe}_{3} \mathrm{O}_{4}$, $2 \%$ of wüstite $\mathrm{FeO}$ and finally $3 \%$ of $\mathrm{Fe}^{0}$, as shown in Tables 1 and 2 . At $700{ }^{\circ} \mathrm{C}$, the main peak with a maximum rate of 3.93 mass $\% \mathrm{~min}^{-1}$ is due to the fast conversion of haematite to magnetite, while a broader peak with a rate of 2.56 mass $\% \min ^{-1}$ shows that conversion of magnetite to wüstite and to metallic iron is taking place. This can be explained for example by the differences in densities of different forms of iron oxides and therefore limitations in oxygen diffusion through the layers of reduced species during reduction. In other words, at the beginning of the reduction reaction the reduction gas removes the dense layer of $\mathrm{Fe}_{2} \mathrm{O}_{3}$ and now the reducing gas can easily penetrate the inside of the particles through the new layer and react with internal metal oxide. The observed fast reaction $\mathrm{Fe}_{2} \mathrm{O}_{3} \rightarrow \mathrm{Fe}_{3} \mathrm{O}_{4}$ supports the fact that densities of magnetite are lower compared to haematite, at 5.17 and $5.24 \mathrm{~g} \mathrm{~cm}^{-3}$, respectively. Next, the significant slowdown in the reaction rate is due to the higher densities of produced layers, i.e. 5.74 and $7.87 \mathrm{~g} \mathrm{~cm}^{-3}$ for wüstite and metallic Fe, respectively. Another explanation for that behaviour might be the thermodynamics of the iron oxide system, within CLC conditions.

For the natural sample, the reduction rate was evidently low at 1.27 mass $\% \mathrm{~min}^{-1}$ at the maximum, detected at $7.0 \mathrm{~min}$ of reduction, because of the observed phase composition (Table 2). At this point, a mixture of $\mathrm{Fe}_{3} \mathrm{O}_{4}$ and $\mathrm{FeO}$ appeared, a result which was supported by the calculations of oxygen capacities. Further reaction led to partial reduction in the material, and at the end of the reduction stage (ca $30 \mathrm{~min}$ ) the sample was mostly reduced to metallic iron with some admixture of wüstite.

Furthermore, the clear difference between samples is the conversion time. For complete conversion, 13.7 and $27.2 \mathrm{~min}$ are required for the natural and synthetic samples, respectively. In other words, more oxygen can be delivered to the fuel in a significantly shorter time (1.98 times shorter).

The effects of process temperature on the reaction rates were also studied. A comparison of selected reduction rates (the lowest and highest temperatures used) is shown in Fig. 5. It is clear that the temperature had a positive effect, since it has to a huge extent changed both the rates and the reaction time. An increase in temperature of $250{ }^{\circ} \mathrm{C}$ caused rates to increase up to 5.71 and $4.61 \mathrm{mass}^{2} \mathrm{~min}^{-1}$ and reaction time to shorten to $15.5 \mathrm{~min}$ (1.75-1.13 times shorter). In addition, it can be estimated that the reduction reaction character has changed. From Fig. 6, it can be seen 

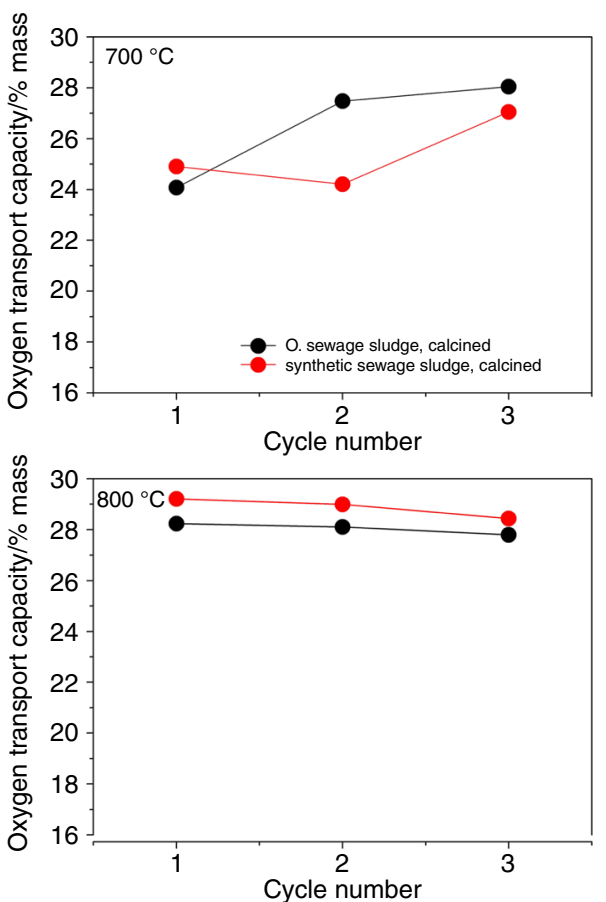

4Fig. 5 Oxygen transport capacity calculated from TG data as a function of both redox cycle number and CLC temperature for sludge from coking plant $\mathrm{O}$ wastewater and from model wastewater

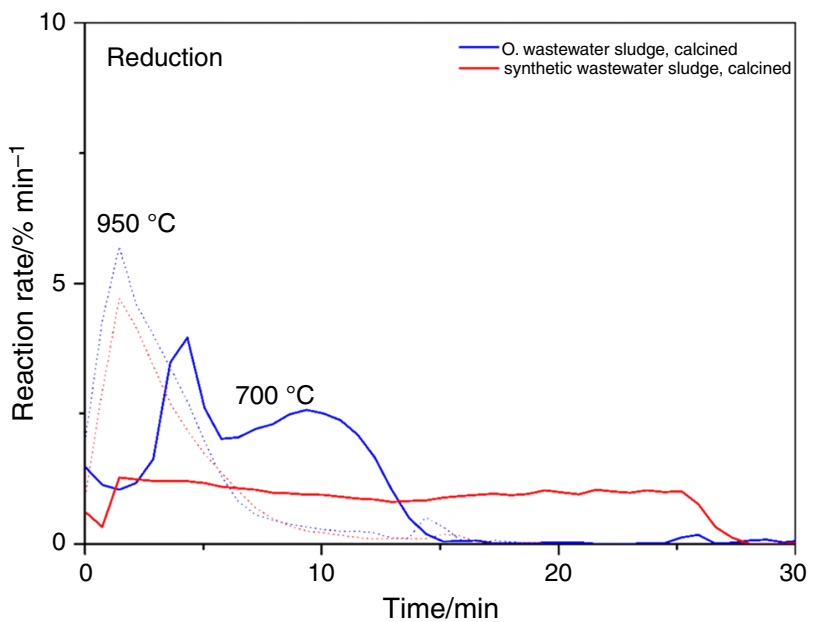

Fig. 6 Reduction reaction rates at $700{ }^{\circ} \mathrm{C}$ and $950{ }^{\circ} \mathrm{C}$ for sludge from coking plant $\mathrm{O}$ wastewater and sludge from model wastewater

that both curves have the same character. This is because the shape change for both materials is due to the transformation of $\mathrm{FeOOH}$ while the sample is heating in the TG chamber and the final presence of $\mathrm{Fe}_{4}\left(\mathrm{Fe}(\mathrm{CN})_{6}\right)_{3}$ only, which is supported by XRD examination (see, for example, Fig. 1).

The functional aspect of the material was also evaluated, i.e. the oxygen carrier's ability to regenerate. As described in "Experimental" section, a stream of $\mathrm{O}_{2} / \mathrm{Ar}$ was used for oxidation (regeneration) of the samples. For the developed material, regeneration time was relatively short compared to reduction reaction time. At $700{ }^{\circ} \mathrm{C}$, complete conversion was achieved within $2.2 \mathrm{~min}$, while at $950{ }^{\circ} \mathrm{C}$ it was achieved in $4.7 \mathrm{~min}$, in both samples. The regeneration reaction rates were estimated to be 18.5 and $11.9 \mathrm{mass} \% \mathrm{~min}^{-1}$, at the lower and higher temperatures studied, respectively. This behaviour means that for regeneration of prepared oxygen carrier materials, the use of lower temperatures, around $800-850{ }^{\circ} \mathrm{C}$ is more suitable (Fig. 7).

Summarizing, more favourable characteristics for oxygen carriers made from wastes were observed, with higher oxygen transfer ability as a function of the cycle number and the temperature of the CLC process, compared with the product obtained from model wastewater sewage. This means that products made from sludge generated during electrocoagulation of wastewater from coking plants have more useful characteristics. They are more stable with temperature and can transfer more oxygen to the fuel. In 


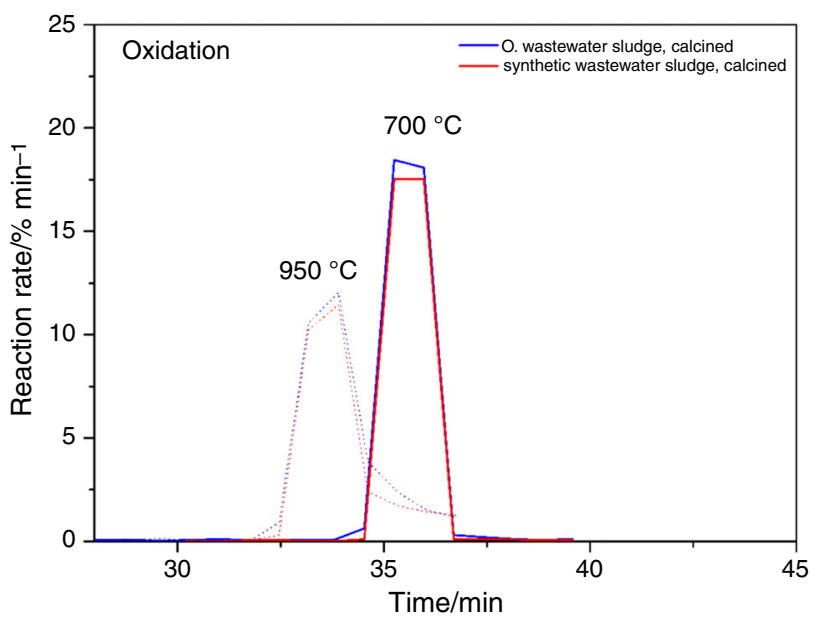

Fig. 7 Oxidation reaction rates at $700{ }^{\circ} \mathrm{C}$ and $950{ }^{\circ} \mathrm{C}$ for sludge from the $\mathrm{O}$ coke oven wastewater plant and sludge from model wastewater

addition, a smaller negative effect of high temperatures on the CLC performance is observed.

Recently, industry has also been interested both in increasing the energy efficiency and in reducing the quantities of fuels consumed in many manufacturing processes. For this reason, the materials presented in this paper might be considered as materials enabling the use of lower fuel quantities during clean energy generation.

In order to detect any structural or morphological changes and also to determine the stability of OCs in repetitive CLC cycles, the SEM EDS analysis was carried out. Figure 8 shows typical SEM images of OC made from coking plant $\mathrm{O}$ wastewater. The microphotographs are taken for: fresh, calcined and reacted OCs after regeneration The samples were obtained within conditions described in "Experimental" and "Instrumentation" sections. The SEM images of the surface of the samples were taken at different magnifications, which are $300 \times$ and $1200 \times$. The EDS analysis confirmed the chemical composition of the carriers and supported results obtained from both ICP-OES and XRD testing. These samples are mixtures of different grain size and types, which are reflecting their complex phase composition. The fresh and calcined samples showed similar morphology, which is clear from Fig. 8. Mostly, they contain the rectangular grains with well-shaped chips forms. The sizes of the grains are varying between 100 and $300 \mu \mathrm{m}$, to be mostly $\mathrm{FeO}(\mathrm{OH})$ and $\mathrm{Fe}_{2} \mathrm{O}_{3}$. Among them, there are a large number of fine particles below $50 \mu \mathrm{m}$ which are detected by EDS to be $\mathrm{Fe}_{2} \mathrm{O}_{3}$ and other minor phases from Table 1 .

However, reacting in TG chamber led to extensive morphology changes in the samples. Now, the grains are in the form of the plates. It is clear that different types of the plates are observed. All of them have a significantly improved surface area and are characterized by diverse subgrain forms. Both-spongy plates with round subgrains and long, needle-like forms have been observed. The closer look at the SEM images with magnification $1200 \times$ shows their complex morphology. These forms were detected to be $\mathrm{Fe}_{2} \mathrm{O}_{3}$ and $\mathrm{Fe}_{3} \mathrm{O}_{4}$. By comparing the morphological characteristics of the particles shown in Fig. 8, it can be concluded that the repetitive reduction-oxidation reactions significantly affected the crystalline structure of the materials and improved the pore structure, which might be attractive in terms of increasing the surface of OC exposed to the fuel. However, this should be controlled by adequate CLC process conditions, or otherwise may lead to extensive samples wearing and loosing.
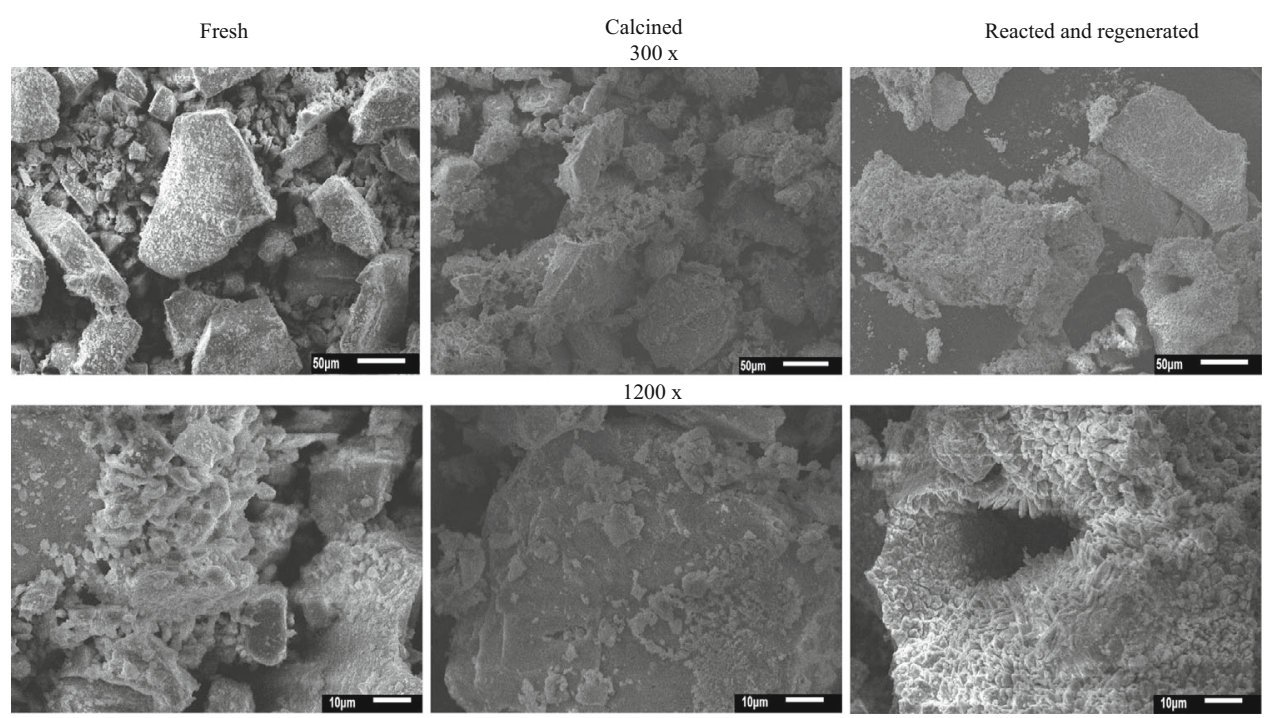

Fig. 8 SEM images for sludge obtained from the O coke oven wastewater plant at different magnifications (300X and 1200X) 
The analysed TG data showed that obtained materials might be reactive under CLC conditions. Therefore, the next step was to study electrocoagulation process itself. It was investigated to choose the optimal parameters for obtaining the desired product. Three variants were analysed. The electrocoagulation process was carried out to determine whether the sequence of introducing additional oxygen via an aeration step and continuous stirring during wastewater electrocoagulation influenced the final product reactivity.

The samples were prepared as described in the "Material characterization" section. They were analysed using TG, as shown in Fig. 9 .

Based on the cyclic redox test carried out in the TG chamber, it can be seen that all the three samples are reactive, both with the fuel and with the oxygen. Furthermore, they are reactive over the whole studied temperature range of $700-950{ }^{\circ} \mathrm{C}$.

As for previous samples, some mass decrease is observed while heating the samples to the reaction temperature.

Deep insight into reactivity can be achieved by studying the behaviour of the oxygen capacity parameter during cycling, and also by increasing the process temperature, as shown in Fig. 10.

The oxygen transport capacity as a function of redox cycle number for sludge samples from coking plant wastewater, when different electrocoagulation conditions were applied at $700{ }^{\circ} \mathrm{C}$, shows that the lowest capacity observed for the sample was 21.0 mass\%. For this sample, a 15-min electrocoagulation process was carried out with solution stirring, and then the solution was aerated for a further $15 \mathrm{~min}$. Very similar capacities were observed for the two samples where the conditions were: two-stage electrocoagulation for $15 \mathrm{~min}$ with stirring of the solution and then a second stage of 15-min electrocoagulation

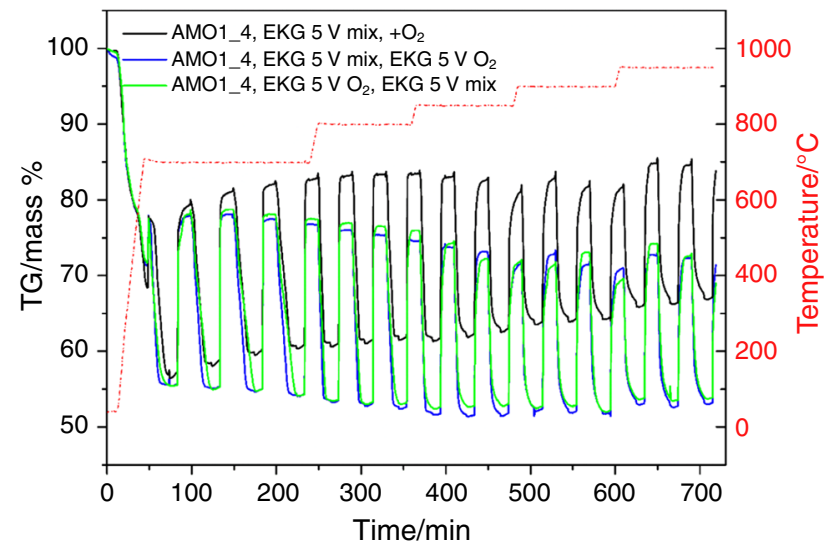

Fig. 9 Comparison of thermogravimetric cyclic analysis of OC samples obtained using different synthesis procedures
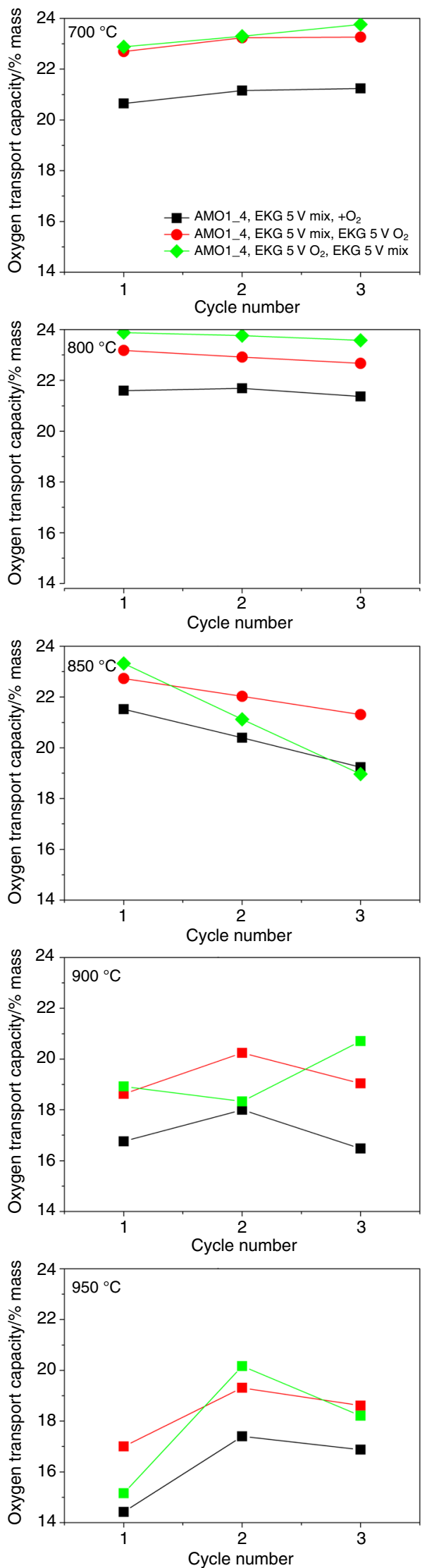
4Fig. 10 Oxygen transport capacity as a function of redox cycle number and temperature for sludge samples from coking plant wastewater when different electrocoagulation conditions were applied

where the wastewater solution was aerated for sample 2 and the opposite order of electrocoagulation stages for sample 3. These capacities were 23.01 mass $\%$ and 23.31 mass $\%$, respectively. This behaviour means that for oxygen carriers, increased capacities might be obtained for electrocoagulation when stirring and aeration processes are both used. Increasing the process temperature leads to some increase in capacities $\left(800^{\circ} \mathrm{C}\right)$. However, further increasing the reaction temperature to $900{ }^{\circ} \mathrm{C}$ and $950{ }^{\circ} \mathrm{C}$ leads to a decrease in capacities. At these temperatures, initial activation of all samples is observable. In other words, some increase in capacity with an increase in cycle number is observed, followed by a decrease in capacity. This tendency might be due to material structure changes, such as an increase in porosity from the first cycle to the second and a slight agglomeration from the second cycle to the third.

Based on the analysis of capacity behaviour, oxygen carrier conditions can be selected. The most stable material is the one where electrocoagulation with stirring is carried out first, and the second electrocoagulation stage includes aeration. Therefore, this is the recommended method of OC production. Furthermore, for OCs obtained from AMO wastewater, the $700-800{ }^{\circ} \mathrm{C}$ temperature range is recommended for fuel combustion process applications.

The proposed utilization of wastes for CLC power generation processes in the form of solid-state oxygen carriers is a matter requiring special attention. This is due to the numerous methods of pollutant removal and processing, and their further application. The environmental impact of the coking plant market is huge. The published data show that there are over 560 coke oven plants in the world, with almost 400 of them located in China. The annual worldwide generation of coke oven wastewater from coking plants during the processing of coke oven gas and from the recovery of coal derivatives is huge. It is estimated to be $75 \times 10^{7} \mathrm{~m}^{3}$ annually [18].

\section{Conclusions}

In this paper, the results of a study on a promising combustion technology known as chemical looping combustion (CLC) were shown. The novel oxygen carrier materials were analysed in terms of their practical applications with gaseous fuel/air for CLC. The sludge from wastewater from the coking process was prepared by electrocoagulation of wastewater. The electrocoagulation method is proposed in order to clean up the wastewater from the industrial process, while the obtained sludge shows a superior composition, making it readily available as an oxygen carrier material. In this paper, materials showed stable performance at temperatures as high as $1000{ }^{\circ} \mathrm{C}$. The effect of waste treatment prior to examination was analysed. This showed that the preferred condition is when electrocoagulation takes place in two stages: first with mixing of the wastewater and the brownish sludge, and then with aeration of the solution.

The Prussian blue iron oxyhydroxide and $\mathrm{Fe}_{2} \mathrm{O}_{3}$ were detected by XRD as responsible for carrying oxygen to the fuel in the chemical loop. Based on the analysis of TG data, chemical stability was observed.

A beneficial aspect of the presented solution is the practical management of waste material sediments by converting them, in a way that does not require many operations, to a material that can be used as an oxygen carrier. We showed an example of rational resource management and an innovative way of reusing the wastes generated in a coking plant as a secondary raw material in the production process of products having a usable value. The utility of chemical sludge from coke wastewater treatment plants is mainly based on the use of a simple method of obtaining carriers, safe use of industrial sewage sludge, the savings associated with avoiding the need to deposit sludge as landfill and, above all, the significant benefit in terms of environmental protection. Accordingly, the solution can be widely used in the field of wastewater treatment and professional power engineering.

This is the first report on the possible utilization of coke plant wastewater sediments in the power industry.

Detailed analyses of the manufactured product were carried out, including fuel combustion tests and assessment of the reactivity of the oxide product developed, using TGQMS, chemical composition analysis by ICP-OES, grain size distribution, melting temperature in a high-temperature furnace with an IR camera, phase composition by XRD and homogeneity and morphology tests by means of an optical microscope. The obtained oxygen carrier is characterized by: a very good average transport capacity of oxygen of 27.27 mass $\%$ at $850{ }^{\circ} \mathrm{C}$, reproducibility of redox results, good regeneration capacity, an optimal temperature range of $800-850{ }^{\circ} \mathrm{C}$, short time of oxidation (2.2-4.7 $\mathrm{min})$, good resistance to high temperatures, relatively low production costs and good availability of the raw material base due to the origin of the raw material, i.e. waste materials. The final product obtained from the elaborated electrocoagulation procedure from coke wastewater has more favourable characteristics than the product made from model wastewater: a significantly shortened fuel combustion time, and reaction rates increased by two to four times. This behaviour in practice 
has a positive effect on reducing the time for the process, enabling the generation of electricity and heat from the combustion of fuels in the chemical looping in a considerably shortened time. Oxygen carriers obtained from the wastes exhibited a good reactivity performance, demonstrating that they may be potentially promising candidates as OC materials for CLC.

Acknowledgements The investigations in this paper were carried out within INNOWATREAT project that has received funding from the Research Fund for Coal and Steel under Grant Agreement No. 710078 and from The Ministry of Science and Higher Education Poland from financial resources on science in 2016-2019.

\section{Compliance with ethical standards}

Conflict of interest The authors declare that they have no conflict of interest.

Open Access This article is distributed under the terms of the Creative Commons Attribution 4.0 International License (http://creative commons.org/licenses/by/4.0/), which permits unrestricted use, distribution, and reproduction in any medium, provided you give appropriate credit to the original author(s) and the source, provide a link to the Creative Commons license, and indicate if changes were made.

\section{References}

1. Wang $\mathrm{Y}$, Wang $\mathrm{X}$, Hua $\mathrm{X}$, Zhao $\mathrm{C}$, Wang $\mathrm{W}$. The reduction mechanism and kinetics of $\mathrm{Fe} 2 \mathrm{O} 3$ by hydrogen for chemicallooping hydrogen generation. $\mathrm{J}$ Therm Anal Calorim. 2017;129(3):1831-8. https://doi.org/10.1007/s10973-017-6267-7.

2. Ishida M, Jin H. A novel chemical-looping combustor without NOx formation. Ind Eng Chem Res. 1996;35(7):2469-72. https:// doi.org/10.1021/ie950680s.

3. Guo L, Zhao H, Wang K, Mei D, Ma Z, Zheng C. Reduction kinetics analysis of sol-gel-derived $\mathrm{CuO} / \mathrm{CuAl} 2 \mathrm{O} 4$ oxygen carrier for chemical looping with oxygen uncoupling. J Therm Anal Calorim. 2016;123(1):745-56. https://doi.org/10.1007/s10973015-4904-6.

4. Pishahang M, Larring Y, Adánez J, Gayán P, Sunding M. Fe2O3Al2O3 oxygen carrier materials for chemical looping combustion, a redox thermodynamic and thermogravimetric evaluation in the presence of H2S. J Therm Anal Calorim. 2018. https://doi. org/10.1007/s10973-018-7422-5.

5. Wang B, Li H, Ding N, Shen Q, Zhao H, Zheng C. Chemical looping combustion characteristics of coal with $\mathrm{Fe} 2 \mathrm{O} 3$ oxygen carrier. J Therm Anal Calorim. 2018;132(1):17-27. https://doi. org/10.1007/s10973-017-6775-5.

6. Nalbandian L, Evdou A, Zaspalis V. La1-xSrxMyFe1-yO3- $\delta$ perovskites as oxygen-carrier materials for chemical-looping reforming. Int J Hydrogen Energy. 2011;36(11):6657-70. https:// doi.org/10.1016/j.ijhydene.2011.02.146.

7. Hou L, Yu Q, Wang K, Yang F, Wu T. Oxidation and reduction kinetic of $\mathrm{YBaCo} 4 \mathrm{O} 7+\delta$ and substituted oxygen carriers. J Therm Anal Calorim. 2018. https://doi.org/10.1007/s10973018-7253-4.

8. Wang B, Xiao G, Song X, Zhao H, Zheng C. Chemical looping combustion of high-sulfur coal with $\mathrm{NiFe} 2 \mathrm{O} 4$-combined oxygen carrier. J Therm Anal Calorim. 2014;118(3):1593-602. https:// doi.org/10.1007/s10973-014-4074-y.

9. Larring Y, Braley C, Pishahang M, Andreassen KA, Bredesen R. Evaluation of a mixed Fe-Mn oxide system for chemical looping combustion. Energy Fuels. 2015;29(5):3438-45. https://doi.org/ 10.1021/acs.energyfuels.5b00048.

10. den Hoed P, Luckos A. Oxidation and reduction of iron-titanium oxides in chemical looping combustion: a phase-chemical description. Oil Gas Sci Technol Rev IFP Energ Nouv. 2011;66(2):249-63.

11. Leion H, Jerndal E, Steenari B-M, Hermansson S, Israelsson M, Jansson E, et al. Solid fuels in chemical-looping combustion using oxide scale and unprocessed iron ore as oxygen carriers. Fuel. 2009;88(10):1945-54. https://doi.org/10.1016/j.fuel.2009. 03.033.

12. Zhang S, Saha C, Yang Y, Bhattacharya S, Xiao R. Use of $\mathrm{Fe} 2 \mathrm{O} 3$-containing industrial wastes as the oxygen carrier for chemical-looping combustion of coal: effects of pressure and cycles. Energy Fuels. 2011;25(10):4357-66. https://doi.org/10. 1021/ef2011595.

13. Ksepko E. Sewage sludge ash as an alternative low-cost oxygen carrier for chemical looping combustion. J Therm Anal Calorim. 2014;116(3):1395-407. https://doi.org/10.1007/s10973-0133564-7.

14. Kwiecińska A, Figa J, Stelmach S. The use of phenolic wastewater in coke production. Pol $\mathrm{J}$ Environ Stud. 2016;25(2):465-70. https://doi.org/10.15244/pjoes/60725.

15. Belkacem M, Khodir M, Abdelkrim S. Treatment characteristics of textile wastewater and removal of heavy metals using the electroflotation technique. Desalination. 2008;228(1):245-54. https://doi.org/10.1016/j.desal.2007.10.013.

16. Mavrov V, Stamenov S, Todorova E, Chmiel H, Erwe T. New hybrid electrocoagulation membrane process for removing selenium from industrial wastewater. Desalination. 2006;201(1):290-6. https://doi.org/10.1016/j.desal.2006.06.005.

17. Akyol A. Treatment of paint manufacturing wastewater by electrocoagulation. Desalination. 2012;285:91-9. https://doi.org/ 10.1016/j.desal.2011.09.039.

18. Kwiecińska A, Lajnert R, Bigda R. Coke oven wastewater-formation, treatment and utilization methods-a review. Proc ECOpole. 2017;11:19-28. https://doi.org/10.2429/proc.2017. 11(1)002.

19. Hubbard CR, Snyder RL. RIR - measurement and use in quantitative XRD. Powder Diffr. 1988;3:74-7. https://doi.org/10. 1017/S0885715600013257.

20. Gustavo N, Roberto A, Andrés S, Mario H. Synthesis and characterization of lepidocrocite and its potential applications in the adsorption of pollutant species. J Phys Conf Ser. 2008;134(1):012023.

21. Ksepko E, Babinski P, Evdou A, Nalbandian L. Studies on the redox reaction kinetics of selected, naturally occurring oxygen carrier. J Therm Anal Calorim. 2016;124(1):137-50. https://doi. org/10.1007/s10973-015-5107-x.

22. Ebbs S, Bushey J, Poston S, Kosma D, Samiotakis M, Dzombak D. Transport and metabolism of free cyanide and iron cyanide complexes by willow. Plant Cell Environ. 2003;26(9):1467-78. https://doi.org/10.1046/j.0016-8025.2003.01069.x.

23. Gehring AU, Hofmeister AM. The transformation of lepidocrocite during heating-a magnetic and spectroscopic study. Clays Clay Miner. 1994;42:409-15. https://doi.org/10.1346/ CCMN.1994.0420405.

Publisher's Note Springer Nature remains neutral with regard to jurisdictional claims in published maps and institutional affiliations. 